\title{
PRESENTE E FUTURO IMEDIATO DAS TELECOMUNICAÇÕES
}

\author{
Vicente Romano \\ Professor de Comunicação Audiovisual e Publicidade da Faculdade de Ciências da Informação da Universidade de Sevilha, na Espanha. \\ Autor, entre outros, do livro Desarollo y progresso - Por una ecologia de la comunicación.
}

$\mathrm{P}$ arafraseando a ironia da zarzuela do início do século que ora termina, poder-se-ia dizer que "hoje as ciências adiantam um despropósito", sobretudo se estão se referindo a isso que, já há vários decênios, vem sendo denominando como Novas Tecnologias da Informação e da Comunicação (NTIC), ou simplesmente Novas Tecnologias (NT). O desenvolvimento destes meios eletrônicos de comunicação caracteriza-se por sua velocidade - medida em nanosegundos, seu diminuto tamanho, daí o novo conceito de nanotecnologias - e pela diversidade de suas aplicações.

No mundo da comunicação, fala-se hoje de multimídia (embora em espanhol seja preferível referir-se a multimeios) e de rede ou redes. Fabricantes, tecnólogos e propagandistas destes meios prometem "um mundo feliz" que quase todos os seres humanos estão prestes a alcançar com os dedos. Assim, entre outras coisas, devido ao desenvolvimento dos computadores, as crianças poderão assistir em um futuro imediato o ensino virtual, numa classe virtual. Os pais alimentarão a família com o teletrabalho no quarto contíguo. Os diretores de empresa discutirão e negociarão por videoconferência, meio pelo qual os professores universitários também ministrarão suas aulas. Os médicos cuidarão de seus pacientes com instrumentos manipulados a distância. Os computadores começarão brevemente a facilitar a vida cotidiana dos portadores de deficiências. Devido à contribuição das inovações eletrônicas, abrem-se novos campos profissionais. E assim sucessivamente. ${ }^{1}$

Parece que este mundo de ficção científica não está muito distante. O que ainda falta é uma rede efetiva que conecte a moradia com os lugares de trabalho. Enquanto isso não chega, alguns empresários de vanguarda já começam a dar os primeiros passos em direção a esse mundo de ficção científica. A título de ilustração, pode servir a nova oferta feita por alguns hotéis de "férias e trabalho".

Este contra-senso, esta contradictio in termini, não é percebido assim por Georg Kiriakides, diretor do Science Technology Park de Creta (www.mitos.com.gr). Os últimos avanços tecnológicos permitem estar de férias no Mediterrâneo e continuar com os negócios a distância. O governo regional desenvolve uma campanha para transformar Creta em uma ilha de "teletrabalho". Vinte hotéis estão colaborando, instalando em suas habitações conexão à Internet, sistemas de videoconferências, fibra óptica de 155 Megabits, serviços de secretariado, de tradução, etc. O telefone com tomada apta para conectar o modem é um dos serviços cada vez mais pedido. Os hóspedes deixam de solicitar o computador, pois a maioria deles viaja com um portátil. Em troca preferem um fax.

O estudo efetuado pelo Empírica - Instituto de Investigação de Mercados, de Bonn - constata a demanda crescente de serviços de Internet e videoconferência nos hotéis. A idéia de telesserviços de G. Kiriakides vai ganhando espaço, muito embora com menor rapidez do que o esperado, em Israel, na Itália e nas Ilhas Baleares. É assim que o capital quer extrair mais valia, até nas horas dos feriados.

As inovações se produzem com tal rapidez e sua imbricação se torna de tal maneira complexa que se faz necessária a reflexão crítica, orientadora, desta evolução. A cada dia se somam, à já transbordante sopa de letras das telecomunicações, novas siglas crípticas que respondem aos últimos lançamentos tecnológicos. E, além de tudo, sempre em inglês, a língua do império. 
Aqui, por óbvias razões de espaço, e a título de ilustração, só são mencionadas algumas das tecnologias cuja introdução está em curso no momento presente, ou estará em futuro imediato.

As uniformes cartas por computador - o correio eletrônico - podem ir acompanhadas já de um padrão caligráfico pessoal. Uma empresa holandesa solucionou o problema da caligrafia pessoal. Envia-se uma amostra que será devolvida em um disquete com uma escritura, a True-Type-Font personalizada, a ser instalada no computador.

Os cartões de visita podem ser confeccionados já através da Internet. Por meio da empresa californiana Iprint Inc., qualquer cliente pode desenhar em alguns minutos, graças à página da rede (www.iprint.com), seus modelos e encomendar produtos impressos para seus negócios. A página é uma mistura de quiosque on line (aberto), escritório de desenho e imprensa digital no ciberespaço (Süddeutsche Zeitung, 29/ 05/99).

No vertiginoso tráfego de dados que circulam pelas "autoestradas da informação", também são freqüentes os engarrafamentos e afunilamentos, como nas estradas verdadeiras. A causa é que as tecnologias inovadoras e os serviços multimídia necessitam de uma extensão de banda correspondente para seu ótimo funcionamento. Diante da crescente afluência de dados, os operadores da rede anunciam já para os próximos meses a instalação da rede de fibra óptica mais rápida da Europa. Através dela, pretende-se conectar os principais centros econômicos e oferecer serviços como aplicações multimídia, comércio eletrônico e radiodifusão digital. Para o ano 2000, deverão estar conectadas 25 metrópoles européias com a rede de banda larga "Ulyses". O objetivo é estabelecer uma rede mundial integrada por 100 cidades de quatro continentes, como pretende a empresa Global Crossing. A chave: nesta rede mundial, inclui-se uma rede pan-européia que é acessível tão-somente aos provedores de Internet.

O futuro da comunicação pode ser descrito com bonitos exemplos, como os videofones celulares, que enviam uma fotografia do lugar em que se está de férias, ou com telefones do tamanho de uma caneta, que reconhecem, segundo o contexto, se devem tocar ou não. $\mathrm{O}$ futuro pode ser descrito também com tecnologias e abreviaturas crípticas como GPRS (General Packet Radio Services), ou HSCSD (High Speed Circuit Switched Data) e outras semelhantes. Essas siglas descrevem celulares e serviços de comunicação da primeira à terceira geração. E o fazem, sobretudo, sob o ponto de vista da transmissão de dados (Georgescu, 1999:4).
Os celulares atuais pertencem ainda à primeira geração, uma vez que transmitem dados à velocidade de 9,6 KBits/s. Esta era a velocidade de um modem de rede fixa há dez anos. GPRS funciona à velocidade de 115,2 Kilobits/s, o que equivale aproximadamente à da rede RDSI (Rede Digital de Serviços Integrados). Esta é a segunda geração, que está prestes a substituir a primeira.

A verdadeira rapidez é proporcionada pela HSCSD, com 144 a 784 Kilobits/s. Esta é a terceira geração que começa a dar seus primeiros passos com a denominação de UMTS (Universal Mobile Telephone System), que irá converter brevemente o telefone celular em uma central de informações que, para o ano de 2002, herdará as funções do computador pessoal. A UMTS deve se converter em um meio de comunicação universal, permitindo o desaparecimento do teclado telefônico e fazendo com que se depositem grandes esperanças no reconhecimento da voz e no MPEG-7 (Motion Picture Experts Group 7). Ninguém mais terá que se sentar diante do microcomputador, tal como é feito hoje. As funções passarão para o UMTS.

A rede de telecomunicações do futuro apresenta-se também como uma estrutura semelhante à do cérebro humano. A tecnologia DIRC (Digital Inter Relay Communication) consiste em estabelecer todo um tecido de estações a cada cinco quilômetros, à maneira das malhas de uma rede de pescador, unidas entre si. Cada participante terá em sua casa uma destas pequenas emissoras de rádio "inteligentes". Algo similar às relações de radioamadores desde muitos anos.

O problema está na segurança. É possível que cada participante possa escutar (ou co-decidir) as conversações que passam por sua estação. Também resulta factível que terceiras pessoas possam escutar as conversas privadas das casas. Os especialistas acreditam que isto não seria nada difícil.

A DWDM (Dense Wavelength Division Multiplexing) permite transmitir três milhões de chamadas por uma fina conexão, que nada mais é que um método para empacotar várias ondas luminosas em uma fibra óptica. A técnica é também apropriada para estabelecer arquivos externos, discos rígidos e aplicativos semelhantes, como as SAN (Storage Area Networks).

$\mathrm{Na}$ verdade, são as empresas quem mais dependem do transporte cada vez maior e mais rápido de dados. Daí o desenvolvimento da VSAT (Very Small Aperture Terminal), que permite transmitir enormes quantidades de dados a um custo previsivelmente elevado.

A última inovação parece ser o renascimento do interruptor, isto é, o uso da rede elétrica como linha telefônica, que permite o acesso à Internet mais rápido do que pela RDSI. 
Na Alemanha, as companhias RWE e Ascom pretendem, em breve, oferecer ao grande público os serviços de telefone e Internet por rede elétrica com seu sistema de comunicação PLC (Power Line Communication). O cliente pode "navegar" devido a um adaptador ligado à tomada.

\section{TELEFONIA}

As tecnologias mais agressivas estão presentes, sobretudo, na telefonia. Seus propagandistas já anunciam o desenvolvimento conjunto do telefone celular e da rede fixa. Acaba o tempo dos cartões de visita cheios de números de telefones: trabalho, casa, telefone celular, correio eletrônico, etc. No futuro, todos terão um só número; a fórmula mágica para isso se chama FMI (Fix Mobile Integration). No verão europeu de 1999, várias companhias telefônicas apresentaram seus novos serviços. A Telecom ofereceu o PCS (Personal Communications Services), um pacote completo de RDSI e conexão via telefonia celular, em que, por um computador de voz chamado call manager, os proprietários da conexão dual podem decidir que telefone deve tocar, se o fixo ou o celular.

Mas, olhando-se mais atentamente, o PCS baseia-se no princípio de funcionamento da RDSI para transferir chamadas. O único "novo" é o "cérebro", o confortável call manager.

Mais interessante ainda foi a oferta da sueca Ericsson, em julho de 1999: o primeiro telefone celular com modo dual, ou seja, os clientes do PCS só necessitam de um número para a telefonia digital do telefone celular e para a rede fixa. Seu elevado preço e o fato de não poder se passar de um a outro durante as ligações são seus inconvenientes.

A Ving Intercom ofereceu neste mesmo mês uma solução mais barata com seu telefone celular E2. Essa companhia estabelece em torno do escritório ou no domicílio do cliente aquilo que se denomina homezone (zona doméstica), em que todas as chamadas são cobradas a preço de telefonia fixa.

Outra possibilidade é a união de todas as conexões em um número pessoal que começa pela série 700. Esses números podem se conservar durante toda a vida, inclusive fora da cidade ou do país. Mas seu preço proibitivo o convertem num luxo acessível somente a poucos.

O SMS (Short Mesage Service) foi desenvolvido para proporcionar informes da bolsa de valores e horóscopos. Atualmente, para os jovens finlandeses, por exemplo, o intercâmbio de informações em textos curtos pelo telefone celular transformou-se em rotina. Telefonam entre 30 e 40 minutos por mês, mas enviam entre 200 e 300 mensagens no SMS. Este tipo de comunicação permite mais liberdade que as chamadas telefônicas. As mensagens podem ser lidas quando se julgue oportuno (Georgescu, 1999:2). Devido ao WAP (Wireless Application Protocol), pode-se regular o intercâmbio de informações entre telefonia móvel e servidores de dados. O WAP, de certa forma o sucessor do SMS, funciona com microbrowsers que reproduzem na minúscula tela do celular o mundo multicor da Internet. Fora as habituais consultas bancárias, oferece a transmissão dos índices da bolsa de valores, ordens de compra ao toque de um botão, pedidos e aquisição de bilhetes de avião, etc. É como transferir o cartão de crédito ao telefone celular.

A febre inicial do IP (Internet Phone) durou pouco. Cerca de $50 \%$ das palavras desaparecem na rede. O futuro desta tecnologia está muito mais em servir de degrau para o desenvolvimento de serviços de comércio eletrônico, teleaprendizagem ou telemedicina.

A norte-americana AT\&T, a segunda companhia mundial de telefonia, marca as tendências para os próximos anos ao autoproclamar-se empresa de cabo (El País, 20/06/99). A solução ao intrincado enredo das telecomunicações parece estar na fibra óptica e no cabo coaxial, e não em cabos multivias. Porém, estima-se que cabear os Estados Unidos com fibra óptica levaria de 20 a 30 anos e custaria entre duzentos e quatrocentos bilhões de dólares. O cabo multivias não é solução ao problema da capacidade devido à finita quantidade de espectro disponível.

Além disso, teme-se um crash para o ano 2000, já eminente, devido ao "efeito 2000". ${ }^{2}$

Para o cidadão comum, entretanto, o problema básico está em como se defender dos preços abusivos e conseguir clareza nos recibos das companhias.

\section{A COMUNICAÇÃO: SETOR ESTRATÉGICO}

A comunicação tem se transformado em um setor estratégico da economia, da política e da cultura. Da guerra, ela sempre o foi. Ultimamente, as páginas dos jornais estão cheias de notícias e manchetes sobre compras, fusões, incorporações amistosas ou hostis e até negras (El País, 20/06/99), grandes concentrações de trusts nacionais e internacionais em plataformas e vias digitais, etc.

A pressa em aumentar os dividendos e a voracidade do benefício privado quiseram emular a velocidade da eletrônica. E não é para menos. No mundo já existem 147 milhões de usuários da rede e, para o ano de 2005, espera-se que 
somem 700 milhões. Na Espanha, dois milhões de seus 40 milhões de habitantes dispõem de computador, mas apenas seis de cada mil espanhóis têm acesso à Internet, segundo o último Informe da ONU, em julho de 1999. Muito pouco, sem dúvida, se comparados aos seis bilhões de habitantes que existem na terra ou ao número de telespectadores do mundo.

De qualquer forma, os mercados europeu e espanhol de telecomunicações parecem consolidar-se. Isso, pelo menos, é o que se afirma repetidamente no segmento. Os especialistas calculam, por exemplo, que logo restarão apenas cinco ou seis grandes companhias telefônicas. À primeira vista, no entanto, o quadro é diferente, pois cada vez mais aparecem novas empresas. Na Alemanha existem 60 delas que competem entre si com preços agressivos.

A rentabilidade continua ainda elevada, mas não é provável que, a longo prazo, todas sobrevivam e obtenham benefícios. A competição é, a cada dia, mais dura e o mercado cresce menos do que o esperado. Não seria de se estranhar, portanto, que as empresas procurem se precaver aumentando de tamanho. Quanto maior uma empresa mais favoráveis serão os custos da técnica e do software das campanhas publicitárias, da distribuição, etc. ${ }^{3}$

O setor das telecomunicações - a indústria da informação - converteu-se num importante setor econômico. Na Alemanha já são 1,72 milhão de pessoas ocupadas no ramo de tecnologia, tanto nos programas e serviços (1,02 milhão) como nos meios (702 mil), o que equivale a 5,1\% da população ativa do país (Süddeutsche Zeitung, 27/04/99). O El País, de 21 de junho de 1999, também declara que o setor de telecomunicações gerou emprego, particularmente qualificado, apresentando o exemplo de algumas empresas, como a espanhola Retevisión, que ampliou a folha de pagamento em 800 trabalhadores, ou a British Telecom e o Uni2, que irão aumentar em 500 e 1.000, respectivamente, seu número de trabalhadores.

Porém, em contrapartida, afirma-se também que a alemã Telecom prevê desfazer-se em cinco anos de mais de 60 mil empregados. A Telefônica, primeira empresa espanhola segundo o critério de benefícios por ano (217 bilhões de pesetas ${ }^{4}$ ), terá para o ano $2000 \mathrm{em}$ torno de 27 mil trabalhadores a menos que em 1996. Em troca, o número de altos executivos terá crescido, no mesmo período, de 79 para 286, e seus salários representarão mais que o dobro (El País, 11/07/99). O exemplo atual mais escandaloso foi a contratação do comissário europeu das comunicações, o alemão Martin Bangemann, por essa companhia. As retribuições destes diretivos em forma de salários, prêmios e bônus, ações e demais prebendas distanciam-se dos salários dos trabalhadores em progressão geométrica, até o ponto de que o diretor da Walt Disney Corporation de Florida poder ter rendimentos anuais superiores aos de seus 4 mil empregados juntos.

A experiência dos últimos anos, pelo menos a espanhola, está longe de satisfazer a todos. Os novos conceitos econômicos de reconversão, reestruturação, flexibilidade, etc., introduzidos e aplicados pelos governos social democratas e "populares", têm se traduzido, até agora, em demissões em massa, antecipações de aposentadoria, insegurança trabalhista, precariedade no emprego, etc. e, sobretudo, no abandono do conceito de serviço público e na privatização dos serviços sociais e das empresas públicas rentáveis. E tudo isto com o consentimento, senão a conivência, dos outrora "sindicatos de classe", que, a partir desta etapa de incerteza, parecem se preocupar unicamente com os poucos trabalhadores fixos que permanecem e com o montante das antecipações de aposentadoria dos que demitem.

As atividades dos Disney, Bertelsmann, Kirch, Murdoch, Berlusconi, Polanco e outros, nas esferas da comunicação rádio-televisão, satélites, editoriais, imprensa periódica, telefonia, Internet, música, cinema, plataformas e estradas digitais, etc. -, demonstram o quanto consideram a comunicação um setor estratégico para a cultura, a consciência e a política.

A inclusão da informação e da comunicação nas estratégias bélicas tem aumentado no correr de milênios. Já no século VII a.C., o chinês Sun Tzu (1981:49) dizia que "toda arte da guerra está baseada em enganar", referindo-se à distribuição de informações falsas. Mas quem mais desenvolveu esse conceito foi o general alemão Von Clausewitz, em seu amplo tratado Da guerra, publicado pela primeira vez em alemão em 1832. No capítulo VI, desse livro, Clausewitz afirma o seguinte: "Una gran parte de las noticias que se reciben en la guerra es contradictoria, otra aún mayor es falsa y la mayor de todas es incierta (...). En suma, la mayoría de las noticias son falsas, y el temor de los seres humanos refuerza la mentira y la no verdad (...) Las personas conscientes que siguen insinuaciones ajenas suelen quedarse indecisas en el lugar; creen haber encontrado las circunstancias distintas a como se las habían imaginado, y, a decir verdad, tanto más puesto que también aquí se vuelven a abandonar a insinuaciones ajenas (...) En la guerra todo es incierto y los cálculos hay que hacerlos con meras magnitudes variables. Dirigen la observación únicamente a magnitudes materiales, mientras que todo el acto de la guerra está impregnado de fuerzas y efectos espirituales". 5 
Trata-se de desinformar, não de informar. A desinformação é a informação falsa, incompleta, desorientadora. É propagada para enganar um público determinado. Seu fim último é o isolamento do inimigo num conflito concreto, mantê-lo em um "cerco informativo".

Os nazistas, com Goebbels à frente, levaram esta estratégia do engano quase à perfeição. Entretanto, atualmente, praticam-se tanto o cerco econômico, militar e diplomático quanto, em especial, o informativo. A criminosa Guerra do Golfo dos Estados Unidos contra o Iraque e a última, não menos criminosa, da Otan, encabeçada pela administração desse mesmo país inominável, ${ }^{6}$ contra a integridade da Iugoslávia: como é sabido, os aviões visíveis e invisíveis destes militares "democratas" encresparam o sarcasmo até o ponto de bombardear repetidamente as estações de rádio e televisão, assim como as imprensas dos jornais iugoslavos em nome da "liberdade de expressão".

Já não se trata apenas de isolar o inimigo, mas de impedir que a própria população receba outra informação que não seja a dele mesmo, de que a "opinião pública internacional" só receba a desinformação produzida pelos Estados Unidos, sem a possibilidade de contrastá-la com outra versão dos fatos ou apenas com os fatos propriamente ditos.

As novas tecnologias permitem aos militares intervir nos conflitos bélicos a distância. Os foguetes da guerra contra a Iugoslávia foram direcionados com ajuda do GPS (Global Positioning System) a partir de um satélite. A telecomunicação militar apoiada em satélites e a eletrônica determinarão as guerras do futuro imediato. Fala-se já de bombas eletrônicas que podem paralisar estabelecimentos neurais da sociedade moderna: hospitais, centrais elétricas, oleodutos, etc. O medo a estas bombas baseia-se em que elas destroem os circuitos eletrônicos. Na Iugoslávia iniciou-se sua utilização, junto às de urânio empobrecido.

Parece que hoje se pode fazer a guerra sem bombas atômicas. As bombas E (eletrônicas) do tipo FCG (Flax Compression Generator) têm o mesmo efeito e já fazem parte dos arsenais de alguns exércitos. Esta bomba E consiste em comprimir mediante uma explosão um campo eletromagnético, como um raio (FCG). Seu emprego não está limitado às grandes potências. Os custos de produção vão desde mil a 2 mil dólares por unidade.

\section{LENTIDÃO DIANTE DA RAPIDEZ}

Os internautas demandam cada vez mais e mais velocidade na transmissão de dados. Os 56 kilobytes por segundo do modem e os $64 \mathrm{KBit} / \mathrm{s}$ de RDSI já não são suficientes.
Mediante a nova técnica ADSL (Asymeteric Digital Subscriber Line), os internautas podem se deslocar com extrema velocidade pela rede. E tudo isso pelo fio normal de cobre da linha telefônica.

Para a comunicação por Internet, esta transmissão assimétrica de dados resulta ideal, pois pode se alcançar até oito megabytes (8 mil kilobytes) por segundo. Em teoria está claro, uma vez que a velocidade de transmissão se reduz consideravelmente quando o computador e as linhas estão sobrecarregados. O projeto piloto instalado na Alemanha alcança valores máximos de 250 kilobytes por segundo. Em fins de 1999, estarão conectadas a esta elevada velocidade 43 redes locais e 70 mil domicílios.

$\mathrm{Na}$ Alemanha existem 4 milhões de conexões à RDSI, e a cada mês somam-se outras 140 mil (Süddeutsche Zeitung, 19/05/99). Trata-se, sobretudo, de domicílios privados que desejam se conectar à economia, isto é, aumentar seus rendimentos e desfrutar das vantagens da RDSI.

Entretanto, olhando-se mais de perto, a RDSI somente integra um reduzido número de serviços, já que a largura de banda é limitada. Cada canal dispõe, no máximo, de 64 kilobytes. Este montante pode ser duplicado se o usuário funde ambos canais da RDSI, o que ainda é pouco para transmitir um pequeno sinal de vídeo de mínima qualidade. Para uma imagem televisiva equivalente à qualidade do vídeo, são necessários de um a dois megabytes por segundo. A RDSI não transmite videoconferências de qualidade; isso sem falar, por exemplo, dos programas de Pay TV (TVs pagas por programa).

Os engenheiros procuram superar estas limitações com o ATM (Asynchronous Transfer Mode), que pode transmitir mil vezes mais dados através da RDSI. Essa técnica permite uma largura de banda muito maior e mais flexível. Lembra bastante a Internet, pois, nesta, cada participante pode prover a rede com qualquer quantidade de informação. Retardamentos e inclusive perdas poderão ocorrer se o volume de dados superar a capacidade do sistema. No ATM, uma capacidade interna regula o fluxo de dados e oferece, ao contrário do que ocorre com a Internet, a garantia de uma determinada qualidade da transmissão.

No ATM, cada fonte deve indicar o tipo e o volume de seus dados. Só lhe é permitida a entrada se houver disponibilidade da capacidade pedida. Os atrasos ou delongas são mínimos e se consegue que, por exemplo, nas videoconferências cheguem a imagem e a voz simultaneamente. Qualquer conversação por satélite demonstra o quanto é desconfortável a adaptação à demora do som. As frações de segundo que os sinais necessitam para ir e vir à 
velocidade da luz são suficientes para desconcertar os interlocutores. Confundem as palavras e perdem o ritmo da conversa.

Até agora, esta tecnologia é oferecida unicamente às empresas. As pessoas privadas e os profissionais não podem usufruir dessa possibilidade. Para eles, a RDSI segue sendo o nível disponível de tecnologia; os preços oscilam entre 1.500 e 10 mil marcos ao mês. A estes valores somam-se, ainda, os custos, nada exíguos, dos equipamentos (hardware), pois, de maneira geral, o ATM pressupõe uma conexão por meio de fibra óptica. Em vista disso, não resta muito da euforia inicial do ATM.

Nos Estados Unidos está se trabalhando pelo desenvolvimento da Internet. Em dois anos, poderiam existir conexões à Internet com qualidade de rede fixa. Quando esse momento chegar, colocar-se-á a questão sobre que tecnologia vai transportar o fluxo de bytes multimídia entre os computadores.

Chegou-se à descoberta da lentidão, de que a RDSI rende pouco e custa muito. Razão pela qual, devido à carestia das conexões, fracassam as promessas do mundo multimeios.

Em um futuro próximo haverá duas classes de usuários na rede: os ricos e os pobres. Após seu início nos Estados Unidos, a Internet 2, com o nome de Abilene, está sendo introduzida também na Europa. Trata-se de uma rede de centros de investigação e universidades, a qual pode transmitir a uma velocidade de 155 megabytes por segundo que custa uns 119 milhões de pesetas ${ }^{7}$ mensais.

Tanta microtecnologia, medida em nanômetros, e tanta velocidade de processamento e transmissão, medida em nanosegundos, que escapam já à percepção humana e, por conseguinte, à consciência. Começa-se a redescobrir o valor da lentidão e a reivindicar seu aprendizado. A qualidade de vida está em contradição com a velocidade de circulação do capital.

O valor da lentidão e seu aprendizado são também reivindicados por Sten Nadolny, em sua novela Die Entdeckung der Langsamkeit, e por Günther Grass, em seu extenso artigo Der lernende Lehrer (Die Zeit, 20/05/99), em que parecem ressoar ecos do brasileiro Paulo Freire.

Grass subscreve o aprendizado da lentidão como contraste ao princípio dominante da aceleração e propõe introduzi-lo na forma de um curso em todas as escolas. A lentidão seria um critério de produtividade, uma espécie de marcha que correria contra o tempo, o adiamento consciente, o freio da velocidade até o repouso e a aprendizagem do ócio - a produtividade do ócio, como diria Paul Lafargue, o genro cubano de Karl Marx.
Nada seria mais útil no contexto da atual inundação de informações que uma introdução à reflexão sem ruídos, sem a rápida sucessão de imagens, sem excesso de ação, e mergulhar na aventura do silêncio, na qual os próprios ruídos internos podem ser vivenciados. Trata-se, é claro, de uma proposta para a qual não há tempo de concretizá-la. Porém, Grass roga que seja levada a sério, e questiona: quem vai ensinar e aprender no futuro sobre aquilo que não é proveitoso, do não economicamente rentável? Queremos a aceleração constante, a contínua perda de sentido, o abandono do imediato, multa em vez de multum? Queremos a retificação digital com cada vez mais desconhecidos em vez de vincularmo-nos e discutirmos com aqueles que têm importância para nós e a quem importamos? Queremos o desaparecimento da atenção no grande ruído e no ofuscamento? Queremos o aumento da "aparência", o deslocamento da realidade experimentável pela "virtual", da excelência e da duração pelo descartável e fugaz?

Com estas perguntas não só se denunciam os novos meios, mas também a ausência de vontade, o orgulho do aprendiz de feiticeiro, o oportunismo e a incapacidade para educálos.

Em suma, é chegada a hora de abandonar a generalização do critério de rentabilidade comercial, o predominante valor de troca, por critérios de rentabilidade social, de qualidade de vida, pelo valor de uso das informações.

\section{A SOCIEDADE VIGIADA}

Devido às chamadas "novas tecnologias da informação e da comunicação", as predições de Aldous Huxley (Admirável mundo novo), de George Orwell (1984) e de Marshall McLuhan (A aldeia global) estão se realizando. Porém, não nos países submetidos à ditadura comunista, uma vez que não há nenhum, mas sim nas sociedades "avançadas" e "democráticas" do capitalismo tardio. A tão tagarelada "sociedade da informação", ou seja, a dos países capitalistas ricos, não é uma sociedade de cidadãos informados, isto é, pessoas que não dispõem dos dados e conhecimentos necessários para atuar de modo inteligente sobre seu entorno; a sociedade em que vivemos e o mundo que os rodeia. Uma sociedade que está se transformando rapidamente em informatizada, vigiada, de cidadãos eletronicamente controlados, analisados e comercializados. Ver e ouvir é tudo. A aldeia global de McLuhan é a sociedade vigiada do futuro imediato.

Os últimos avanços eletrônicos já permitem a vigilância das ligações internacionais ou nacionais por telefone 
fixo ou celular, do fax, telex, correio eletrônico, conexões de Internet, etc.

O Parlamento Europeu aprovou, em maio de 1999, uma diretriz que obriga os provedores de Internet a abrir uma porta (eletrônica) à polícia. Esse sistema de vigilância custará uns 8,5 milhões de pesetas. ${ }^{8}$ Sob a direção do FBI, está em elaboração um sistema homologado IUR (International User Requirement), para ser instalado pelos provedores, que devem arcar com os custos correspondentes.

Porém, esses sistemas normalizados podem constituir um convite aos piratas eletrônicos e à espionagem industrial para superar as medidas de segurança (Süddeutsche Zeitung, 19/ 05/99:7).

Até agora, as novas tecnologias da informação têm reforçado o poder e não a democracia. Ainda não está claro o poder que a tecnologia e as redes midiáticas mundiais exercem. Esta circunstância talvez se deva a que o conceito de poder é utilizado ainda em relação à ação sobre outros. $\mathrm{O}$ poder aplica-se às pessoas e pressupõe um objeto, sua possessão e seres humanos submissos. Para ser efetivo, o poder não só tem que ser atribuído a alguém, como também deve ser reconhecido como tal. Pressupõe que o impotente possa aprová-lo ou rejeitá-lo. Quando falta esta alternativa, falase de violência.

Entretanto, essa relação modifica-se com os meios de comunicação de massa. O poder neles baseado atua de forma oculta e difusa, sob a superfície do papel e da tela. Como regra geral, o destinatário não nota como se consegue ou se fabrica sua aprovação (Romano, 1998).

$\mathrm{Na}$ atual sociedade informatizada, poder é ver sem ser visto e escutar sem ser escutado. A retificação eletrônica da sociedade, com formas de comunicação heterodeterminadas e os chamados meios interativos, multiplica, individualiza e descentraliza o olho do Grande Irmão (Orwell).

Desde que as tecnologias da informação democratizaram (só até certo ponto) a elaboração, armazenamento e distribuição de dados, as autoridades governamentais competem com os poderes extra-estatais: empresas, grupos terroristas e associações criminais. As empresas e instituições privadas utilizam as novas tecnologias para vigiar eletronicamente seus trabalhadores: observam o ritmo de trabalho na tela; pegam amostras dos correios eletrônicos; armazenam dados sobre eles; desenham perfis de seus clientes; etc., que logo circulam no mercado livre.

Se esfumam ou desaparecem os limites entre Estado e sociedade, público e privado, militar e civil, limites sobre aqueles sob quem se constituiu a sociedade burguesa. A sociedade retificada gera outra relação com o poder, pois este opera de maneira difusa e pessoal, utilizando conexões horizontais e uma comunicação adaptada ao usuário.

Sim, as novas tecnologias da informação produzem enormes benefícios, aumentam a produtividade, melhoram a prevenção do crime e a assistência médica, proporcionam um entretenimento alucinante e conforto. Mas ao preço de perder mais e mais intimidade (The Economist, 01/05/99).

A maioria das pessoas aceita dar alguma informação sobre elas para votar, trabalhar, comprar, retirar um livro da biblioteca. Porém, hoje também se considera um aspecto essencial da sociedade civilizada controlar quem possa saber o que for de quem quer que seja. Dispor de certo direito à intimidade é o que tem marcado as diferenças entre democracia e ditadura. Sem o direito a ser deixado em paz, a se desconectar dos olhos, ouvidos e impropriedades do governo e da sociedade livre de mercado, outras liberdades políticas e civis resultam frágeis.

Atualmente, a maioria das pessoas das sociedades ricas acredita que, se está acatando a lei, tem o direito a desfrutar de sua intimidade. Enganam-se. A transformação tecnológica corroeu-a de tal maneira que, ante o crescente poder de prover e difundir dados por meios eletrônicos, cabe se perguntar se dentro de 20 anos restará algo da intimidade que requeira ser protegido.

No momento atual, a principal ameaça à intimidade não vem dos meios de comunicação, mas do computador. As inovações efetuadas no campo da eletrônica permitem não só dispor de informação como também facilmente armazenála, analisá-la e utilizá-la de formas até há pouco impensáveis. Todo uso do cartão de crédito, fax ou correio eletrônico pode ser recolhido, guardado, analisado e utilizado com fins policiais e comerciais. $\mathrm{O}$ mesmo é feito pelas câmeras de TV em circuitos fechados ou nas ruas das cidades. O comércio desta informação aumenta dia-a-dia. Uma só empresa, a Acxiom Corporation, dos Estados Unidos, possui informação vendável sobre $95 \%$ dos domicílios norte-americanos. Há alguém que ignore que o seu uso de Internet é gravado por alguém em algum lugar do mundo? Pergunta-se The Economist.

Informação é poder, portanto não é de se estranhar que governos e empresas privadas se esmerem tanto por usar as tecnologias da informação. Os estratagemas e mecanismos utilizados por eles para obter informação dos cidadãos são muito diversos. A Microsoft, por exemplo, empresa de Bill Gates, o homem mais rico do mundo, segundo dizem, instalou um chip em seus produtos que transmitia (e que talvez siga transmitindo) um número único de identificação cada vez que o computador pessoal é conectado à Internet. 
Alguns tecnólogos pensam que os diminutos "besouros" de reconhecimento desenvolvidos pelo exército norte-americano poderiam ser comercializados a curto prazo. Câmeras de vídeo do tamanho de uma vespa poderão se imiscuir algum dia na habitação desejada, fixar-se no teto e gravar tudo que se faça e fale. O âmbito da "biométrica" permitirá identificar as pessoas a partir de sua voz, olhos, ou qualquer parte mensurável de sua anatomia.

Em suma, não há uma só resposta ao dilema colocado pelo conflito entre a intimidade e o poder crescente da tecnologia da informação. Porém, a menos que a sociedade dê as costas, coletivamente, aos benefícios oferecidos pela tecnologia, a menos que se questione se, em nome da qualidade de vida de todos, é socialmente conveniente tudo o que é tecnicamente possível, o "mundo feliz" da rede midiática continuará cerceando o direito do homem a que o deixem viver em paz, a se desconectar da rede e a se relacionar com outros seres humanos, não com máquinas.

\section{OS MEIOS PASSAM, OS TEMAS PERMANECEM}

Os meios eletrônicos, ou o uso que se faz deles, não têm contribuído para reduzir as desigualdades nem a infelicidade humana criadas por eles; pelo contrário, têm aumentado cada vez mais.

Como se pode facilmente observar, os avanços tecnológicos são para as empresas, organismos governamentais de controle e para algumas universidades e centros de investigação dos países ricos. Também se beneficiam certos profissionais e membros das classes acomodadas destes países privilegiados. Entretanto, a maioria de seus cidadãos e a quase totalidade da população do restante do mundo sequer podem sonhar em ter acesso a estas tecnologias. De acordo com o último Informe sobre o desenvolvimento humano, da ONU, em julho de 1999, 19\% da população mundial apropria-se de $91 \%$ do uso de Internet, como ocorre com o restante das riquezas. A brecha entre ricos e pobres amplia-se tanto entre países como no interior das sociedades. Os que carecem de acesso à rede midiática são também sem terra, sem trabalho, sem teto, sem escolas, sem médicos, sem água, sem afeto, e mais e mais "sem".

Ademais, a telecomunicação é comunicação mediada e mediatizada, isto é, submetida por tempo indefinido a sistemas mediais heterodeterminados. Efetua-se fora do âmbito imediato do contato humano, da dicção e contradição, da riqueza comunicativa dos meios primários. Porém, o ser humano necessita, por sua natureza, da relação com o outro, o diálogo, o intercâmbio de pareceres e sentimentos, ou sim- plesmente que o escutem. Na sociedade da comunicação midiática, como agora se diz, esta necessidade humana se vê cada vez menos satisfeita. Daí a população procurar compensar ficticiamente, ou virtualmente, como se diz agora, estas carências, sua solidão, sua incomunicação, através dos meios que o desenvolvimento atual da indústria coloca à sua disposição.

Como se sabe, o rádio e a televisão são usados, preferencialmente, como companhia, embora ilusória, fictícia. Conhecedores dessas carências, alguns empresários perspicazes começaram a abrir suas páginas na Internet aos usuários que queiram se comunicar entre si. Assim, por exemplo, a empresa californiana K-Swiss, fabricante de sapatos, oferece a qualquer pessoa solitária seu K-Swiss-Club para "falar", através do computador, evidentemente, com outras pessoas que sintam a mesma necessidade. Em função dessas conversações, a empresa adquire uma boa visão do estilo de vida dos sócios do clube (eletrônico, virtual). Estes fabricantes de sapatos obtêm, assim, de forma gratuita, informação sobre seus potenciais clientes: seus sonhos, opiniões, comportamentos, etc.

Estes chat-rooms, espaços para conversar, constituem uma verdadeira mina para as estratégias publicitárias. A enorme demanda de chat-rooms na Internet revela a insatisfação de uma das primeiras necessidades humanas nesta sociedade do capitalismo avançado, ou capitalismo tardio: a necessidade de espaços e tempos públicos para a relação social, de lugares para o encontro, para a conversa distendida. É daqui que se pode descobrir o que se tem em comum com os demais: gostos, insatisfações, desejos de mudar as coisas, etc., em suma, de onde pode se gerar a solidariedade. Por isso privatizam-se cada vez mais estes espaços e tempos a fim de fazer negócio com eles e se enriquecer com as carências e os sentimentos humanos.

A empresa Webgenesis Inc. oferece seus chat-services em www.theleglobe.com. Fundada por dois estudantes em 1995, com um capital inicial de 15 mil dólares emprestados por seus pais e amigos, eles estavam firmemente convencidos de que, na comunidade de usuários de Internet, não existe necessidade maior que o intercâmbio entre os seres humanos. Em 1997, os sócios do Globe eram 700 mil; o seu valor atual ascende a várias dezenas de milhões de dólares. "Nosso negócio", admite um dos fundadores, "baseia-se em uma qualidade inata do ser humano. Faça o que fizer, sempre buscará a conversa com o outro, por menor que seja" (Süddeutsche Zeitung, 19/05/99).

Inicialmente, The Globe cobrava 25 dólares anuais. Agora está organizado em distintos fóruns: esportes, via- 
gens, conselhos familiares, amor através da tela, etc. Às assembléias acodem diariamente 120 mil pessoas. Um terço delas procede da Europa, América do Sul, Austrália; $42 \%$ são mulheres.

Aqui desaparecem todas as barreiras que podem obstruir uma conversação cara a cara. Nada tem a menor relação com a cor da pele, idade, posição social ou títulos acadêmicos. As pessoas apresentam-se com sua palavra escrita. Sequer se deduz o sexo de quem escreve pelo endereço eletrônico. $\mathrm{O}$ papo na Internet mata os preconceitos, afirmam seus defensores. Em lugar algum é tão fácil estabelecer contatos com pessoas do mundo todo e lhes contar o que se queira. Os charlatães comunicam-se até que o modem os separe.

Mas em que idioma? Em inglês, a língua do império. Como caldeirão de culturas, este webchat dura muito pouco. As pessoas prontamente saem dos seus nichos habituais. Venham de onde vierem, tendem a se organizar de acordo com quem compartilham os mesmos interesses, os mesmos problemas, as mesmas carências e angústias. E essa comunicação só pode se dar no contato elementar humano, cara a cara.

A incomunicabilidade humana da sociedade da comunicação tecnológica serve às empresas de telecomunicações para aumentar suas vendas e seus dividendos. Isto é o que persegue o seguinte anúncio da Telefônica: "É claro que deve se falar mais com os filhos, mas, quando, se não param em casa? Mas agora o número único de Moviline lhe permite ter até quatro celulares com o mesmo número, pagando apenas uma licença e a quota mensal."

Entretanto, a comunicação vicária da rede midiática põe-se de manifesto quando se contempla o curioso espetáculo, cada vez mais freqüente, de pessoas que vão pelas ruas com o celular colado a uma orelha e gesticulando vivamente com a outra mão, com o corpo e o rosto como se o interlocutor ausente as estivera contemplando. Não significa que estejam loucas nem ensaiando algum número de circo. Singelamente resulta ridículo complementar com gestos as palavras sem a presença da pessoa à qual são dirigidas.

\section{NOTAS}

Traduzido por Pedro Aguerre.

E-mail do autor: vromano@cica.es

1. A propaganda eleitoral espanhola proporcionou um curioso exemplo: o caso da Izquierda Unida de Madri com a fotografia holográfica de seu candidato Angel Pérez. Com seu aspecto de falso executivo (sua barbicha leninista em flagrante contradição com o corte de cabelo e óculos da última moda yuppie), o rosto inquisitivo deste candidato olha sempre de frente, independentemente do ângulo em que esteja sendo olhado, como se fosse o Grande Irmão de Orwell . A dissonância entre imagem e setor da população que pretende representar afugenta em vez de atrair ao potencial votante.

2. N. do T.: Bug do milênio, nome dado à incompatibilidade dos meios informáticos à data terminada em duplo zero; questão parcialmente resolvida, principalmente nas organizações, mas que ainda desperta o temor de um colapso informacional, localizado ou não, de consequiências indefinidas.

3. A este respeito as declarações eufóricas de Polanco em seu jornal El País, de 18 junho de 1999, em que, além de anunciar os novos campos de intervenção econômica do grupo Prisa, como o de música, dizia o seguinte: "As alianças, domésticas ou internacionais, como opção empresarial, estão entre os postulados de partida na definição de nosso Plano estratégico". O mesmo espírito anima a R. Murdoch, unido ao grupo francês Vivendi, ao se lançar com idêntico entusiasmo capitalista ao negócio de Internet (El País, 02/07/99).

4. N. do T.: Cerca de 1,4 bilhão de dólares ao ano.

5. Tradução direta do alemão para o espanhol: Vicente Romano. "Uma grande parte das notícias recebidas na guerra é contraditória, outra ainda maior é falsa e a maior de todas é incerta (...) Em suma, a maioria das notícias são falsas, e o temor dos seres humanos reforça a mentira e a não verdade (...) As pessoas conscientes que seguem insinuações alheias soem ficar indecisas no lugar; acreditam haver encontrado as circunstâncias distintas a como as tinham imaginado e, a bem da verdade, tanto mais posto que também aqui voltam a abandonar-se a insinuações alheias(...) Na guerra tudo é incerto e os cálculos têm que ser feitos com meras magnitudes variáveis. Dirigem a observação unicamente a magnitudes materiais, enquanto todo o ato da guerra está impregnado de forças e efeitos espirituais." (N. do T. tradução livre).

6. Inominável não só pelas infinitas infâmias cometidas contra outros povos ao longo de sua história, desde o extermínio da própria população indígena, até Vietnã, Panamá, Cuba, Nicarágua, Iugoslávia, etc., mas também por ser o único país do mundo que não tem nome próprio.

7. N. do T.: equivalem a mais de 750 mil dólares.

8. N. do T.: equivalem cerca de 55 mil dólares.

\section{REFERÊNCIAS BIBLIOGRÁFICAS}

DIE ZEIT. 20/05/99

EL PAÍS. 20/06/99. $.02 / 0799$. $11 / 07 / 99$.

GEORGESCU, V. Krvptische Kürzel, em SD-Technik, 19/05/99. ROMANO, V. La formación de la mentalidad sumisa. $2^{\mathrm{a}}$ ed. Madri, Endymion, 1998. SÜDDEUTSCHE ZEITUNG. 27/04/99.

Suplemento Technik, 19/05/99. 19/05/99.

N.113, Suplemento Technik, 29/05/99.

THE ECONOMIST. The end of privacy. 1\%/05/99, p.19-23.

TZU, S. El arte de la guerra. Madri, Fundamentos, 1981. 